\title{
Quo Vadis Product Development Strategy of Indonesia Manufacturing Companies
}

\author{
Evo Sampetua Hariandja \\ Business School, Department of Management \\ Universitas Pelita Harapan \\ Tangerang, Indonesia \\ evo.hariandja@uph.edu
}

\begin{abstract}
Globalization weights have started to majorly affect the act of product development over an extensive variety of business. Another worldview has risen whereby organizations are using gifted building groups scattered far and wide to create items in a shared way. Manufacturing companies in Indonesia are confronting the same test and worldwide organizations that is profoundly aggressive and to maintain their prosperity by new product. The goal of this study was investigating the acts of new product development in manufacturing companies by including methodology, process, association, the execution assessment of new product development itself. This study led through overview utilizing the poll that have utilized beforehand with changes balanced with qualities of Indonesia manufacturing companies and interview with executive level in product planning, product engineering, product development, marketing planning and research and development. All out manufacturing companies have taken an interest in this study are 585 companies comprising $63 \%$ domestic investment, $20 \%$ foreign direct investment, and $17 \%$ were spread joint venture and state-owned companies. The results of this study are $60 \%$ of companies concurred with that new product development very overwhelmed by bearing of top management level (top-down) and $40 \%$ concurred with principal. From 585 companies, $30 \%$ to create new markets and diversification of product, $20 \%$ directed new product development to satisfying purchasers' interest, $18 \%$ to build the quality of product. The spending budget for R\&D from sales, $65 \%$ companies designated around $0-9 \%, 20 \%$ around 10 $14 \%$, and $15 \%$ around $15-20 \%$. The strategy of product development of manufacturing companies in Indonesia were new items and mostly derivative products.
\end{abstract}

Keywords-Indonesia, manufacturing, new product development, $R \& D$, strategy

\section{INTRODUCTION}

New product development is analogous to climbing high peaks and steep cliffs, challenging, invigorating, and empowering experience of the people involved. To be able to successfully climb to the top of the cliff, we require a set of tools, neatly arranged plan, and team support each other and work together using a set of these tools when necessary in due course. Successful new products also require a process that is well planned and mature [1]. Team that varies background of diverse disciplines must work in unison to the direction in which the product will be brought and through the Fuzzy Front End process to create products that meet the needs, wants, and desires of consumers. Within the company, new product development is an integrated part of the company's strategic plan. Ansoff and Stewart split the four alternative strategies of new product development [2], namely: first-to-market, followthe-leader, me-too, and application engineering.

Reinertsen [3] and Hariandja [4] stated that the product development process becomes more specialized and dynamic as well as the need to change for the better. The products produced by the company are always moving towards dynamic to satisfy the needs of consumers. Overall new product development is the core engine of growth companies. Therefore, the company is required expertly manage it [4]. As the rapidly changing market in accordance with the development and competitive conditions which are no longer so easy as times past, the companies in Indonesia, especially those engaged in the manufacturing industry are required also to move more quickly in order to satisfy what the consumer desires. A comprehensive study conducted by Information Resources Inc. (IRI) in 2000 showed that of the 21 categories of packaged goods are launched to the market, 52\% fail [5]. These results prove that the new product development requires the right strategy together with the supporting aspects such as human, infrastructure, culture, and continuous innovation.

To be able to survive in the market, the company is always trying in various ways to stay ahead of its competitors by creating a very new product, different process, utilizing the infrastructure of the same or different, requiring new skills, launch derivative products / derivatives to save costs or to creating a product that was radical / breakthrough. New product development is inseparable from the role of top level management pattern top-down or bottom-up depending on how the innovation process to produce those products. In creating products, innovation plays an important role, especially in terms of the effect on the habits and consumer behavior with minor or major effect and competencies and complementary assets of the company with its increase or completely destroy. The innovation consists of incremental, major, strategic, and radical [6].

Indonesia's manufacturing industry at this time to face the level of competition and a great challenge, especially in the ability to create new products as an indicator of success or failure in generating cash and influence the minds of consumers. If not careful, then the chance to win the competition can be detached. Comparative advantage as an indicator of success is no longer a back-bone in winning the 
battle in the world of business that requires high intensity and concentration. Innovation and design are keys to win the competition in the era of creative economy now. Innovations in the development of new products and services becomes key to how large companies can survive and also offset with the process that continually improve the ability and competence on the other.

The study of the indicators of success of new product development in Indonesia has not done particularly telescoped manufacturing industry. For it is very good and gives a direct impact for companies manufacturing for more than learn what the main indicators in the successful development of new products. This study is intended as a learning arena and to contribute in terms of improving Indonesia's competitiveness in the global arena. The focus of this study is based on the strategy applied by the company in the development of new products.

\section{LITERATURE REVIEW}

Indonesia's manufacturing industry was worth IDR 2,097.7 trillion (approx. USD \$156 billion) in 2015, contributing 18.1 percent to the nation's (GDP), up from 17.8 percent of GDP in the first year. In any case, this higher commitment of assembling to the economy is basically brought about by the declining parts of oil and gas, wares, horticulture and mining inside the Indonesian economy. These areas have all seen their parts decay in the midst of tirelessly low product costs. In today's business world, innovation is the key to win the competition in the market. Sophistication brought about by new technologies, product life cycles are shorter and the global economy has added to pressure the company to constantly innovate in order to survive the onslaught of products from competitors. Therefore, companies that innovate will have a better chance to survive, whereas companies that only "silent" and does not follow the changes will be swept away and disappear.

Development of new products, as the main activity in the innovation process in the company has been seen by many researchers as a key factor of success. Shepherd and Ahmed [7] believe that new product development is the key to success, growth and prosperity in the modern enterprise. Ozer [8] also has the same opinion, the new product is vital for companies to be able to survive for a long time.

At present, companies are vying to introduce their new products or services, by producing better products, or products that are completely new and have not been there before. In addition, they also offer faster delivery and lower prices than competitors. The process of developing new products in a company usually intended to apply new technologies, create new markets, extending product life cycles, product diversification to new markets, reduce costs, or to meet the needs of customers.

Successful development of new products will require consideration of the balance between short-term and long-term, the ability and the internal and external constraints, the performance evaluation process and the product on the market, where all factors must be aligned with the objectives and business strategy. To achieve this objective, the company must set up processes and new product development strategy correctly. Type of new products, new product development procedures, organizational structure, and performance evaluation of new products are some of the factors that must be considered in planning and organizing the development of new products to achieve the desired performance.

\section{RESEARCH METHODS}

This study focuses on the manufacturing industry in Indonesia with coverage of scale and size ranging from micro, small, medium and large with the form of ownership of the state, enterprises, domestic investment, foreign direct investment, and the joint venture which is also indicated by the number of permanent employees, the company's revenue, assets of the company and the company's strategy in the development of new products. Categorization of types of new products refers to research conducted [9] includes derivative products, platforms, and radical. The study variables were measured through a questionnaire that has been used by [10] with some modifications to suit the characteristics of the manufacturing industry in Indonesia and from literature related to new product development.

The number of samples obtained from this study is 585 companies. Of the 585 companies are grouped into different types, namely: automotive, electronics, food / beverage, mining, communications, information technology (IT), pharmaceuticals, textiles, consumer goods, engineering, and others. Distributing questionnaires covering centers of industrial area in DKI Jakarta, West Java, Central Java and East Java. Distributing questionnaires carried out by first making contact with the parties directly involved with new product development process in the company. The parties are authorized in this case consists of a manager level up to director level with the field directly related such as: marketing, product engineering, $\mathrm{R} \& \mathrm{D}$, product planning, product development, design, and fields that have a direct link with the development of new products.

\section{RESULTS AND DISCUSSIONS}

Types of manufacturing industries covered in this study consisted of $22 \%$ of industrial food / beverage, $16 \%$ of the textile industry, $9 \%$ industry engaged in handicraft, $7 \%$ of the automotive industry, electronics industry 5\%, and over $38 \%$ move in the industry by category others are: pharmacy, engineering, fiberglass, shoes, furniture, packaging, telecommunications, and information technology. Manufacturing industry coverage obtained in this study has been adequately described the manufacturing industry forum in Indonesia. From preliminary observations also showed that the manufacturing industry is not all that goes into the Directory of Industry Classification Indonesia incorporated into this study. This is due to there are some companies that the research samples do not have divisions and departments of product development, product engineering, product planning, or research and development. Only companies that have divisions and departments mentioned above are targeted for this study.

This profile is shown in Figure 1 below. 


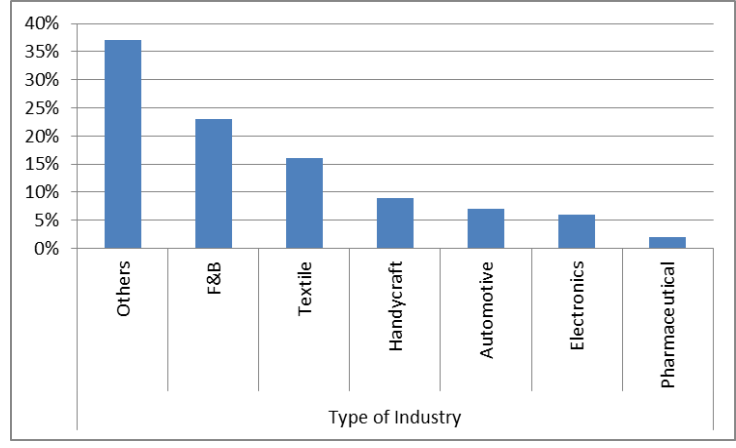

Figure-1. The type of industry

From data processing result that the size of the company there are $13 \%$ of companies are classified as micro, $30 \%$ of small companies, $36 \%$ medium-sized companies, and $21 \%$ of large enterprises as shown in Figure 2 where the data size of the company's group already represents the characteristics of the size of the manufacturing industry located in Indonesia.

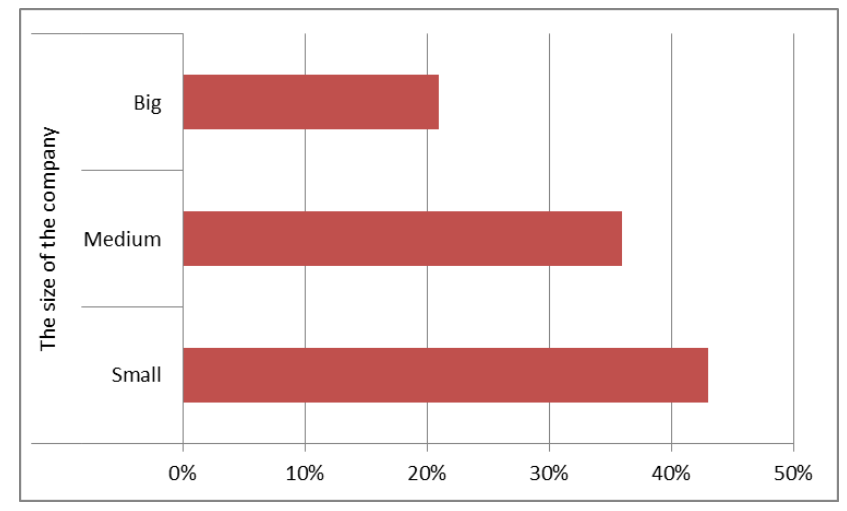

Figure-2. The size of the company

From the type of ownership of the company is shown in Figure 3 below, the profile of respondents consisted of domestic investment 64\%, 20\% FDI, Joint Venture 9\%, and state-owned 5\%. From this data it appears that domestic companies showed high participation in the study and spread largely on the group small, medium, and large.

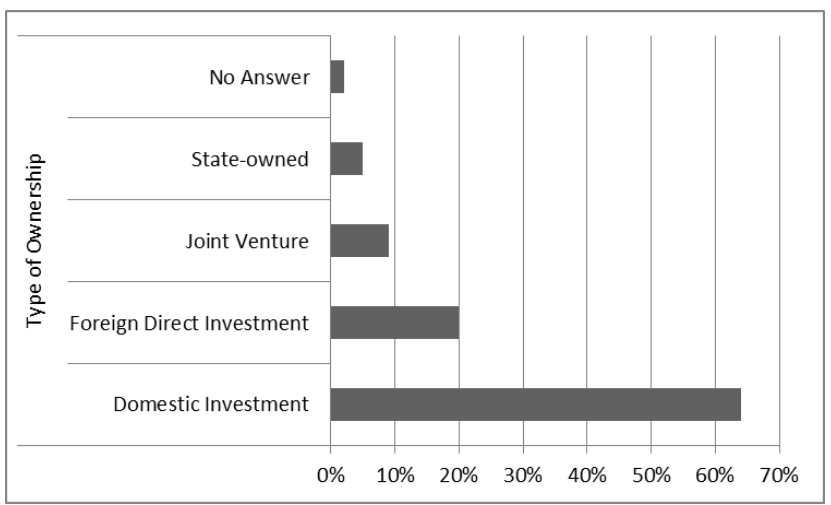

Figure-3. Type of ownership
From the total number of permanent employees, most distributions in the range of companies with a number of employees between 1-250 people to contribute $66 \%$, while companies classified as large of number of employees is only $33 \%$ as shown in Table-1.

Table-1. Total of permanent employee

\begin{tabular}{|c|c|}
\hline Total Permanent Employee & $\%$ \\
\hline $1-19$ & $41.38 \%$ \\
\hline $20-99$ & $12.64 \%$ \\
\hline $100-250$ & $13.79 \%$ \\
\hline $251-500$ & $9.20 \%$ \\
\hline $501-999$ & $10.34 \%$ \\
\hline$>1000$ & $12.64 \%$ \\
\hline
\end{tabular}

Another characteristic that is reflected in the survey of new product development is the scope of the company's business area conducted by the respondent. As many as 53\% of companies making sales in the country, and the rest is exported to various countries dominated by Asian countries $(19 \%)$. It is quite encouraging, because it means that the products that manufactured by the manufacturing industry in Indonesia has a market not only in the country but also abroad, given the fairly competitive business competition.

Of the total respondents, the top-two-boxes 54\% agrees that the products developed very new compared to previous products. Approximately $21 \%$ do not agree that the company considers the products developed are not entirely new. This suggests that in order to be able to compete in a highly competitive market, companies are required to provide differentiation to the product made by a company before. Of the process to create a new product in the company, $36 \%$ support the different processes on the contrary $20 \%$ did not indicate approval. In terms of machining to create new products $28 \%$ more support for the use of the new machine and vice versa $54 \%$ do not support. This proves that not all products are produced and provide differentiation require different processes and machines from the previous. It is influenced by factors of assets, efficiency, infrastructure, and funds needed, and also depends on the scale of the company and scope of its operations. The ability to compete with the processes and limited infrastructure is very heavy in this competitive era. The company strives to conduct its operations with a high degree of efficiency but on the one hand should be able to adapt to the needs of its customers.

Of factors new skills required to make the product, $56 \%$ support that product development requires new skills to be able to produce a quality product, different, and received by the market. Product development strategy undertaken by the company, over $44 \%$ of respondents companies are trying to follow a strategy of first-to-market by developing products that did not exist on the market before. This strategy requires a 
budget that does little and marketing efforts to create innovative products. If seen from product development strategy based on derivatives / derivative, then companies in Indonesia tend to look for opportunities to try to develop a product that does not exist in the market but by following the flow of the previous product with the same platform. This strategy is executed with the aim to save costs and maintain existing networks with more and more using the same components, but still provide differentiation [11].

The ability of innovation to create breakthrough products that are classified / radical, firms in Indonesia still have to learn more to global companies. The study shows that only $24 \%$ of companies that support that they produce a product that was radically contrary to the market and $43 \%$ do not support this. It shows that the innovation process is not running too fast and still requires conduces shape and ride. This fact requires companies manufacturing in Indonesia should be more instrumental to try something new compared to the existing one. Clark and Fujimoto [12] stated that effective product development is not achieved simply by increasing the cost of $\mathrm{R} \& \mathrm{D}$, relies on technology radical or introducing tools and new techniques but a pattern consistent overall view of the system of total development includes organizational structure, technical skills, process completion issues, culture and strategy. The consistencies not only work in broad system architecture but also in the level of detailed work.

New product development cannot be separated from the pattern found in the company's leadership and culture growing in it. Strong leadership can provide the vision, mission and a clear direction in the development of new products. The study shows that in the development of new products, $60 \%$ is always directed by the top management and only $12 \%$ state that rarely directed by top management. For the proposed development of new products, $40 \%$ of respondents always get it from outsiders. From this study, showed results that are rarely landing new product development begins with the bottom-up pattern but proposals outside parties in this case not only consumers but could be other parties involved with the company holding a significant portion. In the economy of creative, sources of ideas from different layers. The involvement of all parties in the development of new products should be the concern of all parts in good company with the pattern of top-down, bottom-up, peer-to-peer, inside-out, or outside-in.

Judging from the company's goals in developing new products, $19 \%$ to meet consumer demand, $16 \%$ to improve the quality, $15 \%$ to create a new market, $13 \%$ to diversify the products, the application of new technology and reduce the cost of production is only $10 \%$, while follow the industry trend of only $9 \%$, and the results of this study support the fact that occur in a competitive era now that satisfy consumer demand to the company goals in order to survive. Drucker [13] stated that the essence of a business is to create customer, customer, and customer. This is in line with the statement of Drucker.

The study conducted on the manufacturing industry in Indonesia as shown in Table 2, shows that of the entire development of new products made by the company, $19 \%$ aim to meet consumer demand. Followed by improving quality (16\%), creating new markets $(15 \%)$, and to diversify the product $(13 \%)$. Reduce the cost of production $(10 \%)$ the next sequence as the company's goal to develop new products, followed by the application of new technologies. Following the trend in the industry was selected by $9 \%$ of respondents and only $7 \%$ who chose to develop new products to extend the product life cycle. Other purposes that do not include goals there is to maintain the gross margin $(0.57 \%)$.

Table-2. The objective of new product development

\begin{tabular}{|l|c|}
\hline \multicolumn{1}{|c|}{$\begin{array}{c}\text { The Objective of new product } \\
\text { development }\end{array}$} & $\%$ \\
\hline Fulfilling the consumer's demand & $18.91 \%$ \\
\hline Increase quality & $16.33 \%$ \\
\hline Create new market & $14.90 \%$ \\
\hline Product diversification & $12.61 \%$ \\
\hline Decrease the production cost & $10.32 \%$ \\
\hline Application of new technology & $9.74 \%$ \\
\hline Follow the trend in industry & $9.17 \%$ \\
\hline Extend the product life cycle & $7.45 \%$ \\
\hline Others & $0.57 \%$ \\
\hline
\end{tabular}

The development of new products require no small cost compared to the cost for other activities such as marketing, production, customer retention, and others. Table 3 below shows the allocation of the budget required by the company's $\mathrm{R} \& \mathrm{D}$ activities. More than $63 \%$ of companies in Indonesia spend R \& D budget is only about $9 \%$ of its annual sales. This resulted in the introduction of new products merely derivative products alone, rarely can produce radicals that are highly loaded with technology and requires considerable cost. New product categories radical, global, technology-based differentiation and future trends have not been part of Indonesia's manufacturing industry. Required commitment, consistency, and coherence to achieve successful performance of new products and qualified.

Table-3. Budget allocation for R\&D

\begin{tabular}{|c|c|}
\hline The average of R\&D budget & $\%$ \\
\hline $0-4 \%$ & $31.76 \%$ \\
\hline $5-9 \%$ & $35.29 \%$ \\
\hline $10-14 \%$ & $20.00 \%$ \\
\hline $15-19 \%$ & $7.06 \%$ \\
\hline$\geq 20 \%$ & $5.88 \%$ \\
\hline
\end{tabular}

Allocation of funds R \& D in the company would be different, depending on the industrial subsector, the number of people involved, the duration of the new product development project, the size of the company and the company's strategy. 
Studies have shown that in general, the manufacturing industry in Indonesia is quite minimal in allocating funds for $\mathrm{R} \& \mathrm{D}$ activities of the company. The lack of funds allocated to R \& D activities showed that the company's commitment to developing new products is not too high.

The company only innovating "moderation" and not willing to create a new product that is "better" than they are today, which is really something different than exist today. In addition, the funds will be minimal causing part of $R \& D$ can't make the necessary technology investments to be able to create new products that can compete in the market. Another impact of fund allocation of R \& D activities is at least a new product development project that is able to be financed by the company. Thus, not surprisingly, the manufacturing industry in Indonesia will produce a new product which is quite small. If the company want to survive in an increasingly competitive global market, it must allocate a larger R \& D so that the ability to conduct research and development of products can be increased, which led to the emergence of innovative products.

Studies conducted in the manufacturing industry in Indonesia shows that type of newly developed products leads to derivative products as shown in Table 4.

Table 4. Type of New product

\begin{tabular}{|l|c|}
\hline \multicolumn{1}{|c|}{ Variable } & Point out of 5 scale \\
\hline Derivatives products & $3.38 / 5.00$ \\
\hline Produk breakthrough/radikal & $2.65 / 5.00$ \\
\hline
\end{tabular}

Associated with the low funding of $\mathrm{R} \& \mathrm{D}$ as described previously, it is not surprising that the type of new products produced by the manufacturing industry in Indonesia leads to derivatives, where the product developed a modification / improvement of existing products today, which was developed to meet the needs of consumers. This supports previous findings that the biggest new product development goals are performed by the industry is to meet consumer demand.

Derivative products have the feature shorter life cycle and low margin aiming to survive in a competitive and saturated market. This is in contrast with breakthrough products/radicals are able to create new markets with high margins, but require resources far greater. Type of derivative products are generally developed by the manufacturing industry in Indonesia resulted in the product does not produce a significant increase in profit due to its low margin $ᄀ$. Although it has different advantages and disadvantages, but these products are relatively the same as competitors. Consumers are sensitive to the comparison between the costs and benefits (cost and benefit) will carefully compare the price to be paid by the benefits. The relatively short life cycle that caused the company to be able to launch new products in a fairly short time anyway. Therefore, in order to maintain and increase corporate profits, the manufacturing industry in Indonesia should begin to direct the development of new products towards products that radical. With the launch of this type of product, even the company will be able to create new markets, because of the unavailability of solutions for consumers prior to the product.

Data collected from respondents indicated that the manufacturing industry in Indonesia is characterized by a low number of new products were successfully launched into the market. A total of $53 \%$ of the total respondents launched less than four products each year as shown in Table 5.

Table 5. Total of new product launch

\begin{tabular}{|c|c|}
\hline Total of new product launch & Percentage \\
\hline $0-4$ & $52.56 \%$ \\
\hline $5-9$ & $21.79 \%$ \\
\hline $10-14$ & $10.26 \%$ \\
\hline $15-19$ & $3.85 \%$ \\
\hline$\geq 20$ & $11.54 \%$ \\
\hline
\end{tabular}

The low number of new products were successfully launched indicates that the manufacturing industry in Indonesia is not active in the business development of a new product or process innovation. These conditions need to be wary of considering the development of new products is a key factor of success to be able to compete in today's business world. With a low number of products launched, it is feared that someday the industry will not be able to survive against the onslaught of new products emerging from abroad, such as China, Malaysia and Vietnam. However, the small numbers of new products related to the allocation of $\mathrm{R} \& \mathrm{D}$ funds are quite small. This resulted in new product development part only able to do research and development in very limited quantities, so that the products succeed not many. Other factors that affect the least number of successful new products launched include the time required and the quality of human resources. As mentioned previously, the time required to complete the new product will be very different depending on the sub-sector of the industry as well as the difficulty of manufacture. The more complicated the process of making a product, and then the time required will be longer. This process can be accelerated by the mastery of technologies that will help people in doing research and product development. The qualities of human resources in the manufacturing industry in Indonesia that will either encourage the emergence of new products are innovative. With the level of expertise and skills and always up-to-date on the latest knowledge, the new range of products can be born. The low number of new products were successfully launched by the manufacturing industry in Indonesia (less than 4 products - 53\%) may mean that the quality of human resources available to date does not support the creation of new products. Companies with foreign ownership would prefer to offices in other countries are considered to have a better quality of human resources to conduct research and development of new products. In fact, to be able to have the skills in this field, human resources have to implement it, so the quality will improve little by little. If the quality of human resources is not corrected, then the new products produced by the manufacturing industry in Indonesia 
will not increase, and they will only do manufacturing alone, according to the new products that have been developed elsewhere.

\section{CONCLUSIONS}

These studies suggest that the focus of new product development in the Indonesian manufacturing industry is on meeting the needs of consumers as key factors in the application strategy rests on the development of a new product category with a budget derived relatively not too large compared to the annual sales of the company as well as the direction of top-level management significantly. To produce a radical, having a clear differentiation, loaded with technology, requires a budget large research and development as well as commitment and consistency coupled with the creation of a conduces environment and innovative organization and collaboration with those universities as research centers and government institutions.

From the above analysis, some conclusions can be drawn as follows:

- In applying the new product development strategy, the company is responsive to the market. Wishes and market changes is a major trigger in determining the direction of new products developed.

- The manufacturing industry in Indonesia was marked by the launch of a new product level is low. $53 \%$ of companies stating only have less than four new products every year, with a focus on derivatives and not radical (breakthrough).

- About $1 / 3$ of companies only allocate less than $4 \%$ of annual sales to fund $\mathrm{R} \& \mathrm{D}$ activities

- Initiatives to develop new products generally come from the direction of the top level management and also from outside

- $61 \%$ of companies have procedures that formal development of new products, but does not have a special unit to handle this event, where $74 \%$ stated that the activity is held by another part.

- Part of marketing a greater role in providing and determine new product ideas, while the R \& D is instrumental in realizing the idea became feasible to produce. Part of production tends to play a passive role, merely implementers.

- In terms of the performance of new products, the implementation of new product development to benefit the company, both internally and externally.

To obtain better results, further studies should involve also companies outside Java, such as Sumatra, Kalimantan, and Sulawesi with samples of diverse manufacturing industries. It also required further study on the service industry in Indonesia to see the differences in the indicators used in the development of new products in terms of strategy, processes, organization, and performance evaluation.

\section{REFERENCES}

[1] J. Cagan \& C.M. Vogel. 2002. Creating Breakthrough Product: innovation from product planning to program approval, Prentice-Hall.
[2] L.C. Morse \& D.L. Babcock. 2007. Managing Engineering and Technology, 4th Ed., Pearson Prentice-Hall International.

[3] D. Reinertsen, D. 2005. "Let it Flow: how lean product development sparked a revolution", Industrial Engineer, Vol. 37 No.6 pp. 40-45.

[4] E. Hariandja. 2004. "Dinamika sistem pengembangan produk baru", SWA-Sembada, Vol. 21 No.16 pp.71.

[5] J. Schneider \& J. Yocum. 2004. New Product Launch: 10 proven strategies, Stagnito Communications, Inc.

[6] C.C. Markides \& P.A. Geroski. 2005. Fast Second: how smart companies bypass radical innovation to enter and dominate new markets, Jossey-Bass.

[7] C. Shepherd and P.K. Ahmed. 2000. NPD Frameworks: A Holistic Examination. European Journal of Innovation Management 3(3): 16074.

[8] M. Ozer. 2000. Information Technology and New Product Development. Industrial Marketing Management 29:387-96.

[9] S.C.Wheelwright \& K. B. Clark. 1992. Revolutionizing Product Development, The Free Press.

[10] Goldense Group Inc. 2004. Product Development Metrics Survey.

[11] E. Hariandja. 2005. "Platform produk: keseimbangan commonality dan distinctiveness", SWA-Sembada, Vol. 21 No.6 pp.66.

[12] K.B. Clark \& T. Fujimoto. 1991. Product Development Performance: strategy, organization, and management in the world auto industry, Harvard Business School-Press.

[13] P.F. Drucker. 2006. The Practice of Management. Harper Business.http://travel.kompas.com/read/2014/02/04/1803414/Kunjungan .Wisman.Terus.Meningkat. Accessed 16th April 2014, at 10.30. 